\title{
The High Sensitivity of Economic Activity to Financial Frictions
}

\author{
Robert E. Hall \\ Hoover Institution and Department of Economics, \\ Stanford University \\ National Bureau of Economic Research \\ rehall@stanford.edu; website: Google "Bob Hall"
}

December 9, 2009

\begin{abstract}
A financial friction is a wedge between the return received by providers of financial capital - ultimately, consumers - and the cost of capital paid by businesses and consumers who use capital. I study two frictions. One raises the rental cost of capital to firms and the other raises the rental cost of housing and durable goods to consumers. My focus is on the effects of financial frictions - I take the magnitudes of the frictions as given. Thus my results complement an active recent literature that explains the intensification of financial frictions in a crisis. I find that financial frictions are powerful determinants of economic activity.
\end{abstract}

\section{This version for reading in color}




\section{Introduction}

Financial frictions drive wedges between savings and investment. These wedges are powerful determinants of economic activity. When a financial crisis increases friction, unemployment rises and output falls. I investigate the magnitude of these effects in a dynamic model with investment in business and housing sectors, calibrated to the financial crisis of late 2008 and ensuing deep recession. The model confirms that increased financial friction had an important role in the dramatic decline in economic activity that occurred in late 2008 and early 2009.

The paper focuses exclusively on the key issue of how financial frictions affect activity. It complements the studies of Cúrdia and Woodford (2009), Gertler and Karadi (2009), and many others, which focus on the circumstances that cause financial crises and the mechanisms that result in worsening frictions in those crises. The starting point for my treatment of frictions is an increase in the cost of capital to investors in business plant and equipment and to purchasers of housing and consumer durable goods. These increases in the cost of capital do not go to the benefit of suppliers of financial capital-rather, they are wedges between the return to saving and the cost of capital. In a reasonably simple macro model, I show how increased wedges dramatically lower output and employment.

I build on the literature emanating from the real business cycle model that retains the emphasis on fully specified formal dynamic general-equilibrium models based on optimizing behavior but alters the model in ways that makes economic activity more sensitive to driving forces. This literature began by trying to match the apparent sensitivity of activity to fluctuations in productivity, then moved on to consider the sensitivity to shocks caused by the central bank. Recently, the literature has incorporated the response to changes in government purchases, where it has emphasized the increased sensitivity in times when the central bank has pushed its target interest rate to the lower bound of zero.

The model in this paper includes consumer durables and residential capital as well as plant and equipment. Households consume the services of durables and housing along with standard goods and services. New houses are produced from standard output by incurring a quadratic adjustment cost.

The model includes a pair of financial frictions. One is a wedge between the borrowing

cost facing business investment in plant and equipment and the lending return facing households. The second is a similar wedge between homeowners' borrowing costs and the lending 
return.

This paper shares some of the analytic framework of Hall (2009a). The model in that paper has a single production sector and a representative family. Three features of the model result in realistic amplification of the effects of driving forces, including government purchases, the single driving force studied. One is a variable wedge between factor payments and product prices. The wedge is not a driving force, though it would be a potent one if it varied spontaneously. Rather, the wedge is an endogenous variable that responds negatively to the level of output. One rationalization for this response is sticky product prices - with the product price held constant, an increase in factor prices squeezes the markup of price over factor cost. The New Keynesian class of macro models embodies this mechanism. A number of other rationalizations have appeared as well.

The second feature of the model is a strong response of employment to the marginal product of labor. The response is not from changes in labor-force participation, but from changes in unemployment. An explicit treatment of unemployment along the lines of Hall (2009b), based on the search-and-matching model with sticky compensation, results in elastic supply of labor to firms. The elasticity arises primarily from the decline in unemployment that occurs when productivity rises, not from an unrealistic propensity for workers to offer more hours or for a larger fraction of the population to participate in the labor market.

The third feature is complementarity of consumption and work. Absent complementarity, most models based on the life-cycle principle predict declines in consumption in response to many types of stimulus, when in fact it appears that consumption does not change. Adding complementarity corrects this defect. Workers consume more when employed than when unemployed because they have less time to produce substitutes for market consumption at home when employed.

\section{Related Research}

\subsection{Wedges as driving forces}

Chari, Kehoe and McGrattan (2007) describe a number of wedges in a general-equilibrium macro model and cite earlier research, mostly dealing with a wedge separating the marginal product of labor from the marginal value of workers' time. They define a financial wedge as the gap between the price received by producers of capital goods and the price paid by investing firms. In a dynamic setting, their definition is quite different from the more 
standard one adopted in this paper, where the wedge is the difference between the interest rate paid by firms and the rate received by households. Their empirical work suggests that this financial wedge had a relatively small role in aggregate fluctuations even including the Depression. One reason is that, in their model, the wedge moves consumption and hours of work in opposite directions. The model in this paper does not have that property. Christiano and Davis (2006) challenge the findings of their paper on a number of grounds, including that their assumed pattern of measurement errors is unrealistic. Hall (2009b) takes a different approach to measurement errors and introduces unemployment explicitly, showing that the labor wedge appears to be quite small, whereas Chari, et al., associate a large fraction of macro volatility with the labor wedge.

\subsection{Interest spreads}

This paper views an increase in financial friction as having two effects: (1) depressing output and employment and (2) raising the spread between, on the one hand, the interest rates paid by private businesses and households borrowing against their houses and other durables interest rates and, on the other hand, the interest rates received by consumers (together with those paid by the government). An extensive literature views this relationship in a forecasting setting: Credit spreads - differences between private and government borrowing rates - and term spreads - differences between long-term and short-term government borrowing rateshave forecasting power for future output and employment. The model in this paper takes the credit spread as a driving force. It generates substantial movements in the term spread because an adverse financial shock lowers short government rates by far more than it lowers long government rates.

Gilchrist, Yankov and Zakrajsek (2009) present extensive evidence about the forecasting power of credit spreads, along with many cites to the earlier literature. Philippon (2009) documents the close relation between bond yields and investment, the channel considered in this paper.

\subsection{How much of the widening of credit spreads in financial crises takes the form of an increase in the wedge?}

Amato and Remolona (2003) decompose total credit spreads into components associated with default probabilities, financial risk, and other determinants, with citations to many 
earlier studies. They show that default probabilities are a small part of the total spread in normal times, especially for bonds with high ratings and low default probabilities. For example, during the financially quiescent period they consider, AAA bonds had average spreads of 74 basis points and default probabilities of 0.6 basis points ( 6 chances in 100,000), single A bonds spreads of 117 basis points and default probabilities of 7 basis points, and single B bonds spreads of 5.1 percentage points and default probabilities of 3.3 percent per year. In normal times, the fact that corporate but not government bonds are subject to state taxation explains a fair amount of the remaining spread, but this component does not rise in times of crisis. Measuring the role of financial risk encounters all the challenges of modern finance and estimates of this component are conjectural. The authors conclude that liquidity - another name for financial friction - is probably reasonably important. I am not

yet aware of any similar breakdowns for the enormous widening of spreads that occurred in late 2008.

\section{$2.4 \quad$ Financial frictions}

Research on financial frictions is far too extensive to discuss fairly here. Stein (2003) discusses many of the issues. Gertler and Kiyotaki (2010) survey the role of finance in macro fluctuations and provide many recent references.

Principal-agent frictions have served as the backbone of macroeconomic models of the effects of financial developments on aggregate output and employment for the past two decades. Many of these models adopt Townsend's costly-state-verification framework.

Most models developed in response to the crisis of 2008 focus on frictions in the principalagent relationship between intermediaries and suppliers of funds, where the intermediary can abscond with some part of the amount provided by the supplier, at the cost of terminating the relationship. The wedge is the spread between the intermediary's lending rate and the rate it pays the suppliers. If the spread is above a critical value, the continuation value to the intermediary exceeds the value available from absconding, so the relationship remains durable. Because the intermediary loses its own equity if it absconds, the spread will be small for a well-capitalized intermediary and large for a highly levered one. An event - such as declines in asset values - that causes a financial crisis lowers intermediaries' equity and raises spreads. Thus financial crises bring higher financial frictions.

Another source of financial friction is debt overhang. Firms with existing debt face a 
higher cost of borrowing when issuing junior debt because the added assets raise the value of the existing more senior debt. Although in principle, an investment project could be financed at market rates by making a deal with the existing debtholders, such deals are almost impossible to make in practice because of holdout. Overhang becomes a more serious source of friction in financial crises.

Kiyotaki and Moore (2008) consider friction arising from liquidity. A firm wishing to invest faces a bottleneck in the rate at which it can raise funds. Anticipating the bottleneck if a favorable investment opportunity arises randomly, the firm keeps money on hand so that it can take advantage of the opportunities. The result is a wedge between the cost of outside funds and the return to investment. Because the money earns a lower return than do investments, the need to park funds as money adds an extra cost that becomes a wedge. In general, theories of liquidity describe wedges that arise from a desire to transact quickly. If a firm wants to raise funds quickly, it will receive the low bid price for its securities and thus grant some amount of added return to the buyer, if the buyer sells later closer to the higher ask price. The wedge is roughly half the amount of the bid-ask spread. These spreads widen during crises.

Akerlof lemon problems also create wedges - see, for example, Hellwig (2008). Lenders and buyers of securities make inferences from the fact that a firm seeks to raise funds. They demand higher returns to offset adverse selection. The fraction of would-be borrowers that are seeking funds to stave off collapse rather than to finance promising investments rises in a crisis, so the wedge widens.

Finally, rationing in credit markets results in wedges in the sense that the shadow cost of funds for rationed borrowers exceeds the return earned by the suppliers. Rationing occurs in equilibrium in models of external financing with adverse selection or moral hazard - see Stein (2003). These forces generally worsen in financial crises.

\section{Basics}

The full dynamic model is sufficiently complicated that I will start with the most basic model that captures the effect of a financial wedge. The basic model has only one kind of capital, plant and equipment, and collapses all of time into a single period. Capital has the role of an intermediate product. The financial wedge has the same role as in Diamond and Mirrlees's classic analysis of the unnecessary inefficiency of the taxation of intermediate products. The 
model is also the stationary version of a simple dynamic GE model.

In this economy, $\delta$ units of output produce one unit of capital, $k$. The price of capital is not just $\delta$, however, but is

$$
p_{k}=\delta+\beta^{-1}(1+f)-1 \text {. }
$$

Here $\beta<1$ is the discount factor in preferences and $f$ is the amount of the financial friction wedge. Even without the wedge, consumer impatience raises the price of capital over its production cost, reflecting the delay between the acquisition and use of capital that occurs in the underlying dynamic model.

Producers have a Cobb-Douglas technology with labor elasticity $\alpha$. The demand for capital is

$$
k=(1-\alpha) \frac{y}{p_{k}},
$$

SO

$$
\frac{y}{k}=\frac{p_{k}}{1-\alpha} .
$$

Thus an increase in the wedge raises the output/capital ratio in proportion to the effect of the wedge on the cost of capital, $p_{k}$.

The output of the economy is divided between consumption $c$ and capital:

$$
y=c+\delta k
$$

SO

$$
\frac{c}{k}=\frac{y}{k}-\delta
$$

The consumption/capital ratio rises by the same amount as the output/capital ratio when the wedge increases.

The production function is

$$
y=h^{\alpha} k^{-1 \alpha}
$$

where $h$ is labor input, so

$$
\frac{h}{k}=\left(\frac{y}{k}\right)^{1 / \alpha}
$$

The labor/capital ratio rises with the output/capital ratio with an elasticity greater than one.

The demand for labor is

$$
h=\alpha \frac{y}{w}
$$


where $w$ is the wage in output units, so

$$
w=\alpha \frac{y / k}{h / k} .
$$

Consumers' first-order condition for balancing goods consumption and work effort is

$$
w c^{-1 / \sigma}=h^{1 / \psi}
$$

where $\sigma$ is the intertemporal elasticity of substitution for goods and $\psi$ is the Frisch elasticity of labor supply. I write this equation as

$$
w\left(\frac{c}{k}\right)^{-1 / \sigma}=\left(\frac{h}{k}\right)^{1 / \psi} k^{1 / \sigma+1 / \psi}
$$

and solve for the level of capital,

$$
k=\left[w\left(\frac{c}{k}\right)^{-1 / \sigma}\left(\frac{h}{k}\right)^{-1 / \psi}\right]^{\frac{1}{1 / \sigma+1 / \psi}} .
$$

Finally, given $k$ from the last step and $y / k$ from the first, I recover the level of output:

$$
y=\frac{y}{k} k .
$$

Figure 3 shows the steps in a set of graphs. The equilibrium without the financial friction is marked with continuous black lines and the equilibrium with a 6-percent annual wedge is shown in dashed lines. The parameters correspond to those used later in the full dynamic model. The upper-left graph translates the difference in the price of capital $p_{k}$ into the corresponding increase in the output/capital ratio. The upper right shows the corresponding increase in the consumption/capital ratio. The middle-left graph shows the increase in the labor/capital ratio and the middle-right graph the decrease in the wage. The bottom-left graph calculates the decrease in the capital stock by solving the household's first-order condition. Finally, the bottom-right graph shows the decrease in output resulting from the increase in the financial wedge.

\section{Dynamic General Equilibrium Model}

The dynamic model in this paper starts from the one-sector neoclassical framework with lifecycle consumption and endogenous labor supply. Consumption includes two components, a direct flow of nondurables and a flow of housing services derived from the stock of housing 

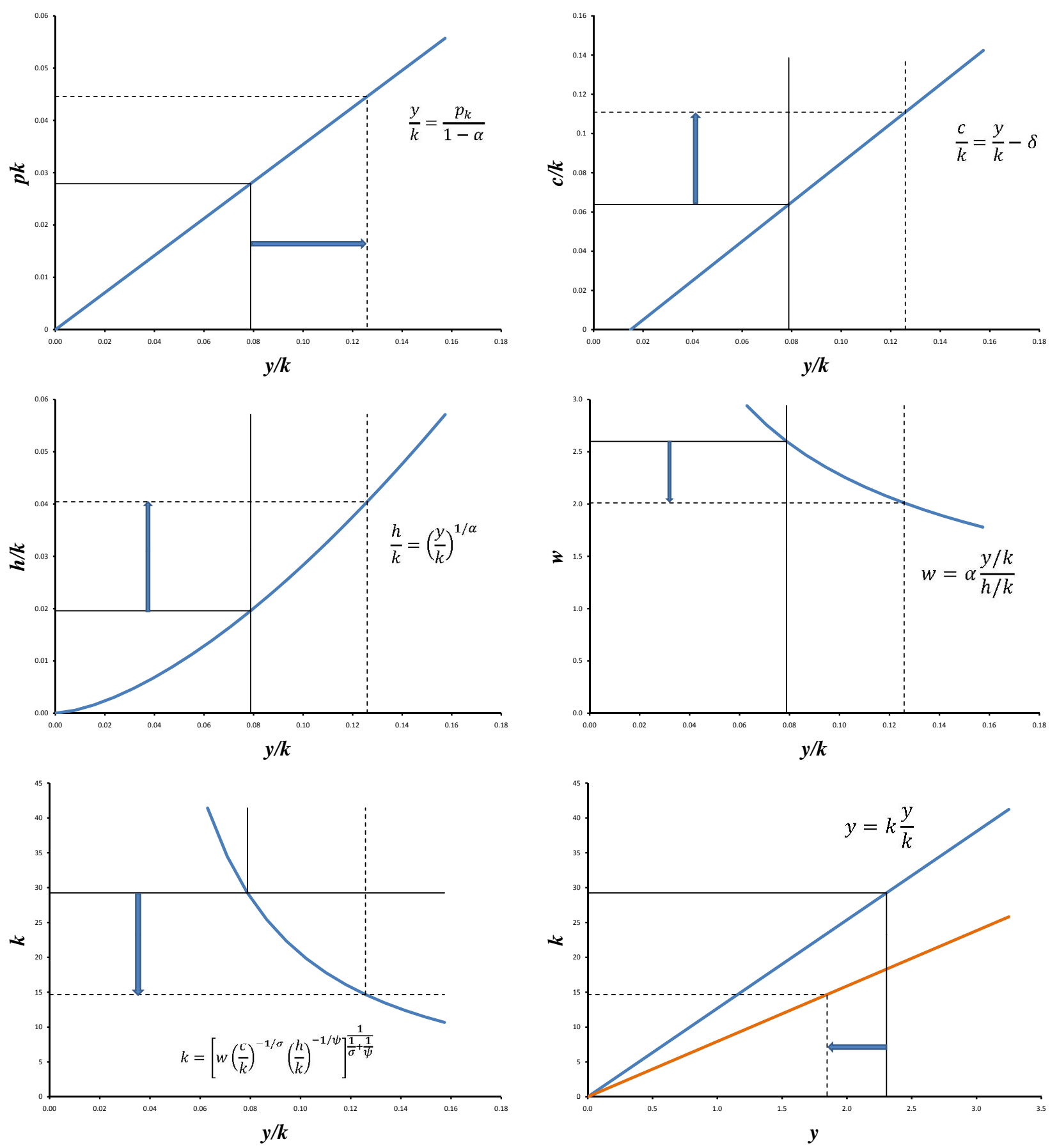

Figure 1: Equilibrium with Financial Wedge 
capital. To keep the analysis simple, I abstract from growth and uncertainty. The economy is closed, so it is effectively a model of the world economy, not a national economy. I introduce two features that combine to amplify the effects of driving forces to seemingly realistic levels: (1) a wedge between the output price and factor prices that declines as output rises and (2) more elastic labor supply than is found in studies of individual behavior. The second feature effectively includes the variations in the unemployment rate that occur in response to driving forces. For an extensive discussion of these two features, see Hall (2009a).

\subsection{Modeling financial friction}

The economy's value at time $t$ for receipts at time $t+1$ is $m_{t}$. The economy's financial market trades one-period debt with interest rate $r_{t}$ from period $t$ to period $t+1$. This rate satisfies the asset-pricing condition,

$$
m_{t}\left(1+r_{t}\right)=1
$$

Thus

$$
m_{t}=\frac{1}{1+r_{t}} .
$$

The discounted cost of the cash flows to a producer from holding a unit of capital from the end of period $t$ to the end of period $t+1$ are

$$
\left(1+f_{t}\right) q_{k, t} p_{y, t}-\frac{1}{1+r_{t}}\left(1-\delta_{k}\right) q_{k, t+1} p_{y, t+1}
$$

Here $q_{k}$ is Tobin's $q$, the price of installed capital relative to the price of uninstalled capital goods $p_{y, t}$ and $\delta_{k}$ is the depreciation rate of capital. The cost $f$ captures the financial friction, a cost of holding capital that is not income to the suppliers of finance. Measured in values as of period $t+1$, the rental price of capital is

$$
p_{k, t+1}=\left(1+r_{t}\right)\left(1+f_{t}\right) q_{k, t} p_{y, t}-\left(1-\delta_{k}\right) q_{k, t+1} p_{y, t+1}
$$

The rent for housing is the same, with subscript $d$ in place of $k$.

I assume that the friction $f_{t}$ has persistence $\rho$ :

$$
f_{t}=f \rho^{t}
$$




\subsection{Technology and preferences}

The technology for producing output $y$ is Cobb-Douglas with labor elasticity $\alpha$ :

$$
y_{t}=h_{t}^{\alpha} k_{t-1}^{1-\alpha}
$$

Firms enjoy a markup of $\mu$ of price $\left(p_{y}\right)$ over cost. A firm maximizes value by setting the marginal revenue product of labor to the wage:

$$
\alpha p_{y, t} \frac{1}{\mu_{t}} h_{t}^{\alpha-1} k_{t-1}^{1-\alpha}=w_{t} .
$$

I solve for hours:

$$
h_{t}=\alpha \frac{p_{y, t} y_{t}}{\mu_{t} w_{t}} .
$$

Note that output is not real GDP. GDP includes both the services of housing, as a component of consumption, and the production of houses, as a component of investment. Here, output is the production of goods, which are used to make houses or are consumed directly.

The markup ratio $\mu$ is a declining function of total output (not the firm's own output):

$$
\mu_{t}=\left(\frac{y}{\bar{y}}\right)^{-\omega} .
$$

Here $\bar{y}$ is the stationary level of output.

The rental price of capital is

$$
p_{k, t}=\left(1+r_{t-1}\right)\left(1+f_{t-1}\right) q_{k, t-1} p_{y, t-1}-\left(1-\delta_{k}\right) q_{k, t} p_{y, t} .
$$

Capital demand in period $t$ equals capital supply as determined in the previous period:

$$
(1-\alpha) \frac{p_{y, t} y_{t}}{\mu_{t} p_{k, t}}=k_{t-1}
$$

Capital installation occurs up to the point where the marginal adjustment cost equals the difference between the price of installed capital $q_{k} p_{y}$ and the price of uninstalled capital, $p_{y}:$

$$
\kappa_{k} \frac{k_{t}-k_{t-1}}{k_{t-1}}=\left(q_{k, t}-1\right) p_{y, t}
$$

The parameter $\kappa$ measures capital adjustment cost - if $\kappa_{k}=0, q_{k}$ is always 1 and there are no adjustment costs. 
Consumption is a Cobb-Douglas composite of consumption of standard output, $c_{y, t}$ and housing services $d_{t-1}$ :

$$
c_{t}=c_{y, t}^{\phi} d_{t-1}^{1-\phi}
$$

I normalize the price of composite consumption at one.The normalization implies

$$
\phi^{-\phi}(1-\phi)^{-(1-\phi)} p_{y, t}^{\phi} p_{d, t}^{1-\phi}=1 .
$$

Housing rents for the price

$$
p_{d, t+1}=\left(1+r_{t}\right)\left(1+f_{t}\right) q_{d, t} p_{y, t}-\left(1-\delta_{d}\right) q_{d, t+1} p_{y, t+1} .
$$

Here $q_{d, t}$ is the price of a unit of installed housing - Tobin's $q$ for housing. Housing installation occurs up to the point where the marginal adjustment cost equals the difference between the price of installed housing $q_{d, t} p_{y, t}$ and the price of uninstalled housing, $p_{y, t}$ :

$$
\kappa_{d} \frac{d_{t}-d_{t-1}}{d_{t-1}}=\left(q_{d, t}-1\right) p_{y, t}
$$

The parameter $\kappa_{d}$ measures housing adjustment cost.

At the beginning of a period, the stock of installed capital is $k_{t-1}$ and the stock of housing is $d_{t-1}$; people choose hours of work $h_{t}$. At the end of the period, output $y_{t}$ becomes available and is allocated to government purchases $g_{t}$, consumption of goods $c_{y, t}$, and investment in capital and housing, including adjustment cost, resulting in the new capital stock, $k_{t}$ and new housing stock $d_{t}$. The equation for the economy's material balance is

$$
k_{t}+\frac{\kappa_{k}}{2} \frac{\left(k_{t}-k_{t-1}\right)^{2}}{k_{t-1}}+d_{t}+\frac{\kappa_{d}}{2} \frac{\left(d_{t}-d_{t-1}\right)^{2}}{d_{t-1}}=\left(1-\delta_{k}\right) k_{t-1}+\left(1-\delta_{d}\right) d_{t-1}+y_{t}-c_{y, t}-g_{t} .
$$

Worker-consumers order their paths of hours and composite consumption according to the utility function

$$
\sum_{t} \beta^{t}\left(\frac{c_{t}^{1-1 / \sigma}}{1-1 / \sigma}-\chi c_{t}^{1-1 / \sigma} h_{t}^{1+1 / \psi}-\frac{h_{t}^{1+1 / \psi}}{1+1 / \psi}\right)
$$

where $\sigma<1$ and $\chi \geq 0$ controls the complementarity of consumption and hours. Note that I normalize the weight of the $h$ term relative to the $c$ term at one; this amounts to determining the units of $h$ relative to the units of $c$.

The first-order condition for the optimal mix of composite consumption and work is:

$$
w_{t} c_{t}^{-1 / \sigma}\left[1-\chi(1-1 / \sigma) h^{1+1 / \psi}\right]=p_{c, t} h^{1 / \psi}\left[-\chi(1+1 / \psi) c^{1-1 / \sigma}-1\right]
$$


The discounter is

$$
m_{t}=\beta \frac{c_{t+1}^{-1 / \sigma}}{c_{t}^{-1 / \sigma}} \frac{1-\chi(1-1 / \sigma) h_{t+1}^{1+1 / \psi}}{1-\chi(1-1 / \sigma) h_{t}^{1+1 / \psi}} .
$$

The Euler equation for consumption is

$$
\left(1+r_{t}\right) m_{t}=1
$$

The demand for the goods component of consumption satisfies:

$$
p_{y, t} c_{y, t}=\phi c_{t}
$$

and similarly for the housing component:

$$
p_{d, t} d_{t-1}=(1-\phi) c_{t}
$$

\section{Parameters}

Table 1 gives the values of the parameters I use in the base case of the model, together with the sources for the values.

For the three parameters of preferences, $\sigma, \chi$, and $\psi$, I solve the equations relating the parameters to the own Frisch elasticities of consumption and labor supply and to the observed difference between consumption by workers and non-workers. I draw the values from the appendix to Hall (2009b). The equations appear in Appendix B to this paper.

The parameter $\omega$ controls the amplification of shocks - it is the negative of the elasticity of the markup of price over cost with respect to output. Positive values of $\omega$ imply that a force that raises output also diminishes the wedge associated with market power. Hall (2009a) shows that positive values of $\omega$ (or some other amplification mechanism), together with moderately elastic effective labor supply, are needed to explain the response of output to changes in the government's purchases of goods and services. I use the value $\omega=1.03$, which delivers the realistic government purchases multiplier of 1.0. Note that this value is somewhat higher than in the model of my earlier paper, which did not include housing and durables.

I use a standard value for the adjustment cost for plant and equipment - see Hall (2004) for cites. In terms of Tobin's model of investment relating the percent change in the capital stock to the deviation of Tobin's $q$ from its normal value of one, the coefficient is 0.5 at annual rates. That is, for every percentage point that $q$ exceeds normal, investment over a 


\begin{tabular}{|c|c|c|c|}
\hline Parameter & Explanation & Value & Source \\
\hline$\sigma$ & $\begin{array}{l}\text { Consumption curvature } \\
\text { parameter }\end{array}$ & 0.41 & $\begin{array}{l}\text { See text--calculated from Frisch elasticities } \\
\text { and consumption reduction of nonworkers }\end{array}$ \\
\hline$\chi$ & Complementarity parameter & 1.01 & $\begin{array}{l}\text { See text--calculated from Frisch elasticities } \\
\text { and consumption reduction of nonworkers }\end{array}$ \\
\hline$\psi$ & Hours curvature parameter & 1.66 & $\begin{array}{l}\text { See text--calculated from Frisch elasticities } \\
\text { and consumption reduction of nonworkers }\end{array}$ \\
\hline$\beta$ & Utility discount factor & 0.987 & Annual rate of 5 percent \\
\hline$\varphi$ & $\begin{array}{l}\text { Share of nondurables in } \\
\text { composite consumption }\end{array}$ & 0.82 & $\begin{array}{l}\text { Ratio of nondurables and services } \\
\text { consumption to total consumption plus } \\
\text { residential construction, NIPA table 1.1.5, } \\
\text { average from } 1980 \text { through } 2007\end{array}$ \\
\hline$\alpha$ & Labor share & 0.646 & NIPA Table 1.10 \\
\hline$\kappa_{k}$ & $\begin{array}{l}\text { Adjustment cost for plant and } \\
\text { equipment }\end{array}$ & 8 & Hall (2004) and research cited there \\
\hline$\kappa_{d}$ & $\begin{array}{l}\text { Adjustment cost for durables } \\
\text { and houses }\end{array}$ & 8 & $\begin{array}{l}\text { Picked to match observed response of durables- } \\
\text { housing expenditure relative to plant and } \\
\text { equipment--see text }\end{array}$ \\
\hline$\delta_{k}$ & $\begin{array}{l}\text { Depreciation rate of plant and } \\
\text { equipment }\end{array}$ & 0.0188 & $\begin{array}{l}\text { BEA Fixed Asset Tables, ratio of depreciation } \\
\text { to net stock, } 2000 \text { to } 2008\end{array}$ \\
\hline$\delta_{d}$ & $\begin{array}{l}\text { Depreciattion rate of durables } \\
\text { and housing }\end{array}$ & 0.0129 & $\begin{array}{l}\text { BEA Fixed Asset Tables, ratio of depreciation } \\
\text { to net stock, } 2000 \text { to } 2008\end{array}$ \\
\hline$\omega$ & $\begin{array}{l}\text { Elasticity of markup ratio with } \\
\text { respect to output }\end{array}$ & 1.03 & See text \\
\hline$\rho$ & $\begin{array}{l}\text { Quarterly persistence of } \\
\text { financial friction }\end{array}$ & 0.60 & Inferred from corporate bond spreads--see text \\
\hline
\end{tabular}

\section{Table 1: Parameter Values and Sources}


year is enough to raise the capital stock by 0.5 percent. At annual rates, the corresponding value of the parameter $\kappa_{k}$ is the reciprocal, 2 , and the corresponding quarterly value is four times higher, or 8 . Models of adjustment cost for plant and equipment usually describe internal adjustment - costs incurred within a firm to install new capital. The relationship would apply to external adjustment cost as well. When adjustment is external, buyers of capital goods pay outside sellers a price $q$ that fluctuates relative to the costs of those sellers. Adjustment friction then takes the form of short-run rents that sellers of capital goods enjoy when investment demand is strong.

Adjustment costs in consumer durables and housing are always modeled as external costs. Tobin's $q$ for durables and housing is the price that buyers pay for cars and houses. I use the value of $\kappa_{d}$ that roughly matches the relative percent declines in plant and equipment investment that occurred during the 2008 crisis. Because these are about equal, I use $\kappa_{d}=8$.

\section{Quantifying the Frictions in the Crisis of 2008 and Its Aftermath}

Immediately after the critical events of mid-September 2008, the spread between private borrowing rates and the rates the federal government paid rose dramatically. The spread has three components: (1) the expected default rate, (2) the difference in financial risk (covariance with the economy's stochastic discounter), and (3) the financial friction. Presumably all three rose during the crisis of late 2008, so the increase in the spread is an upper bound on the increase in the financial friction.

Rationing of lending for new borrowing appears to have been important in financial markets in late 2008, so the observed spread for new borrowing understates the effective spread facing a given borrower. Thus it would seem most appropriate to measure spreads from the valuation of existing debt. One of the thickest market for traded claims on private entities is the corporate bond market, so I use data on the prices of corporate bonds to measure the change in spreads in late 2008. Bond prices reflect the economy's discounter for private claims well into the future. To measure the time path of the spread, I rely on the model to project the path of the discounter, use it to value a claim on the cash flows from a corporate bond (equal semiannual interest payments plus return of capital at maturity), and calculate the spread between the yields corresponding to the calculated bond prices.

Table 2 provides data on spreads for BAA- and AAA-rated corporate bonds and for 


\begin{tabular}{lccccc}
\hline \hline & \multicolumn{5}{c}{ Bond yields } \\
\cline { 2 - 6 } & $\begin{array}{c}\text { 20-year Treasury } \\
\text { bonds, constant } \\
\text { maturity }\end{array}$ & Moody's BAA & $\begin{array}{c}\text { Spread } \\
\text { over } \\
\text { Treasurys }\end{array}$ & Moody's AAA & $\begin{array}{c}\text { Spread } \\
\text { over } \\
\text { Treasurys }\end{array}$ \\
\cline { 2 - 6 } 1987 through 2006 & 5.91 & 7.51 & 1.60 & 6.70 & 0.79 \\
December 2008 & 3.18 & 8.43 & 5.25 & 5.05 & 1.87 \\
Change & -2.73 & 0.92 & 3.65 & -1.65 & 1.08 \\
\hline \hline
\end{tabular}

Table 2: Bond Spreads

20-year Treasury bonds. Historical default rates are low in the BAA category and virtually nonexistent in AAA bonds, which are instruments issued by select corporations whose historical payment records are only slightly poorer than the federal government's. It compares the averages of yields and yield spreads for 20 fairly calm years, 1987 through 2006, to corresponding figures in December 2008, at the peak of the financial crisis. The Treasury yield declined by 2.73 percentage points, while the BAA corporate rate rose by 0.92 points and the AAA corporate rate fell by 1.65 percentage points. The BAA spread over Treasurys rose by 3.65 points and the AAA spread by 1.08 points.

Table 3 calculates the persistence of the increase in spreads, an important parameter in the model. The excess spreads - values in December 2008 in excess of their normal values in the prior 20 years - were 3.65 percentage points for BAA bonds and 1.08 points for AAA. By October 2009, the excess spreads were 0.53 and 0.20 points. These figures were 14 and 18 percent of the December excess spreads. The implied quarterly persistence rates are $\rho=$ 56 and 60 percent $\left(\rho^{10 / 3}=0.14\right.$ for BAA and 0.18 for AAA). I use the 60 percent figure for the calculations in this paper.

Using this estimate that the financial friction responsible for the widened spread declines back to normal at 40 percent per quarter, I find that spreads in 20-year bonds of the observed magnitudes correspond to gigantic values of the friction wedge $f_{t}$ in the early periods of the crisis. A value of $f=0.015$, corresponding to a wedge of 6 percentage points at the outset, generates a 20-year spread of only 30 basis points, one quarter of the observed increase in the spread for super-safe AAA bonds in December 2008 over historical levels.

If the initial financial shock is three times as big, $f=0.045$, so the initial wedge is 18 percentage points at an annual rate, the 20-year spread is 89 percentage points, still below 


\begin{tabular}{lcc}
\hline \hline & $\begin{array}{c}\text { Moody's } \\
\text { BAA }\end{array}$ & $\begin{array}{c}\text { Moody's } \\
\text { AAA }\end{array}$ \\
\cline { 2 - 3 } Spread from 1987 through 2006 & 1.60 & 0.79 \\
Spread in December 2008 & 5.25 & 1.87 \\
Spread in October 2009 & 2.13 & 0.99 \\
Excess spread in December 2008 & 3.65 & 1.08 \\
Excess spread in October 2009 & 0.53 & 0.20 \\
Ratios, October 2009 to December 2008 & 0.14 & 0.18 \\
Quarterly persistence rate & 0.56 & 0.60 \\
\hline \hline
\end{tabular}

Table 3: Estimating the Persistence of the Shock to Spreads

the actual increase in the AAA spread of 108 basis points and far below the increase in the spread for BAA corporate bonds of 3.65 points. As I will show shortly, a shock of this magnitude causes not a great recession, but close to a depression.

Figure 2 shows the spreads of two 30-day borrowing rates for nonfinancial commercial paper, one top rated (AA) and the other lower-rated (A2/P2). Only well-rated companies borrow in the commercial paper market; the AA rating corresponds to AAA or AA ratings for bonds and the A2/P2 rating corresponds to single A or BBB. The rise in the spread for lower-rated commercial paper is easily in line with the initial wedge of 6 percentage points that I use.

\section{Response to Transitory Financial Friction}

The model functions at two quite different speeds. If one of the capital stocks is displaced from its stationary value, it returns slowly, over decades, back to the stationary level. Appendix D describes the slow dynamics of capital adjustment. On the other hand, a transitory shock to a driving force, such as the financial friction, results in movements at roughly the speed of decay of the shock. I display these movements in impulse response functions over a three-year span. To the extent that a shock and subsequent recovery leave one or both of the capital stocks away from its stationary value, slow capital adjustment comes into play. Thus some of the impulse response functions do not return to the stationary values at the end of the three years, but rather to values that converge slowly over subsequent decades.

The impulse response functions show the equilibrium of an economy with perfect foresight that starts with a financial friction above its normal level (taken to be zero). Decision 


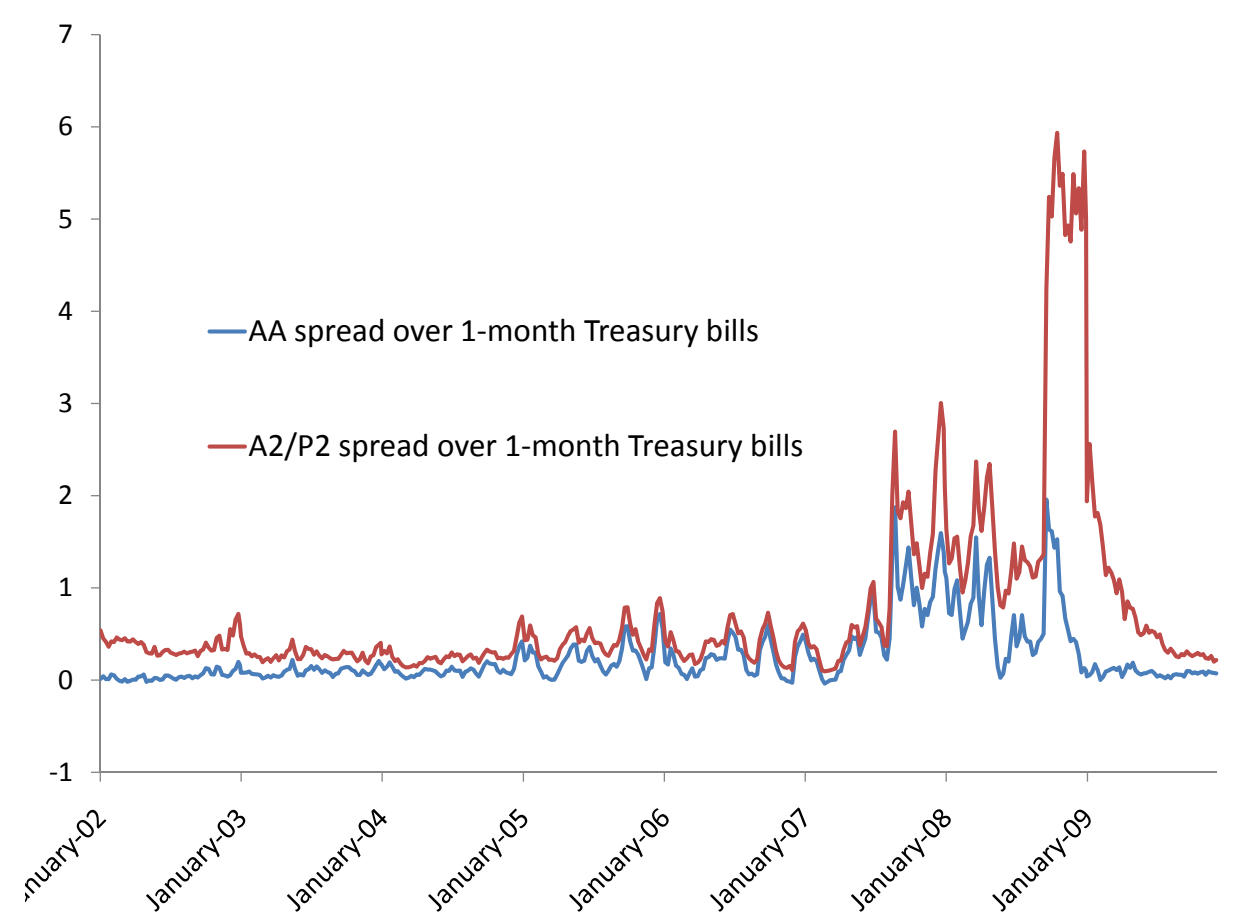

Figure 2: Credit Spreads for Commercial Paper, 2002-2009

makers know that the friction will die off at the persistence rate $\rho$ over future quarters. Experience has shown that these perfect-foresight paths give reasonably accurate estimates of the response in a fully stochastic model, provided that interactions with uncertainty are not important. Further, for small shocks, the results of this exercise are the same as those found from log-linearization of a stochastic model.

I consider the response to a friction that affects both types of capital. The friction declines from an initial level $f$ with a rate of persistence of $\rho=60$ percent per quarter:

$$
f_{t}=f \rho^{t}
$$

I take $f=0.015$, corresponding to a 6 percentage point initial shock $f$ at an annual rate. As noted in the previous section, this shock is far smaller than the increase in the spread of corporate bond yields over Treasury yields that occurred in late 2008 .

Figure 3 shows the response of the components of output to the transitory financial friction. The immediate decline in output is just under 5 percent. The decline is concentrated in the two types of investment. Plant and equipment investment falls by 13 percent and durables-housing by 15 percent. Nondurables consumption falls by just over one percent (this category includes services apart from the service value of housing). 


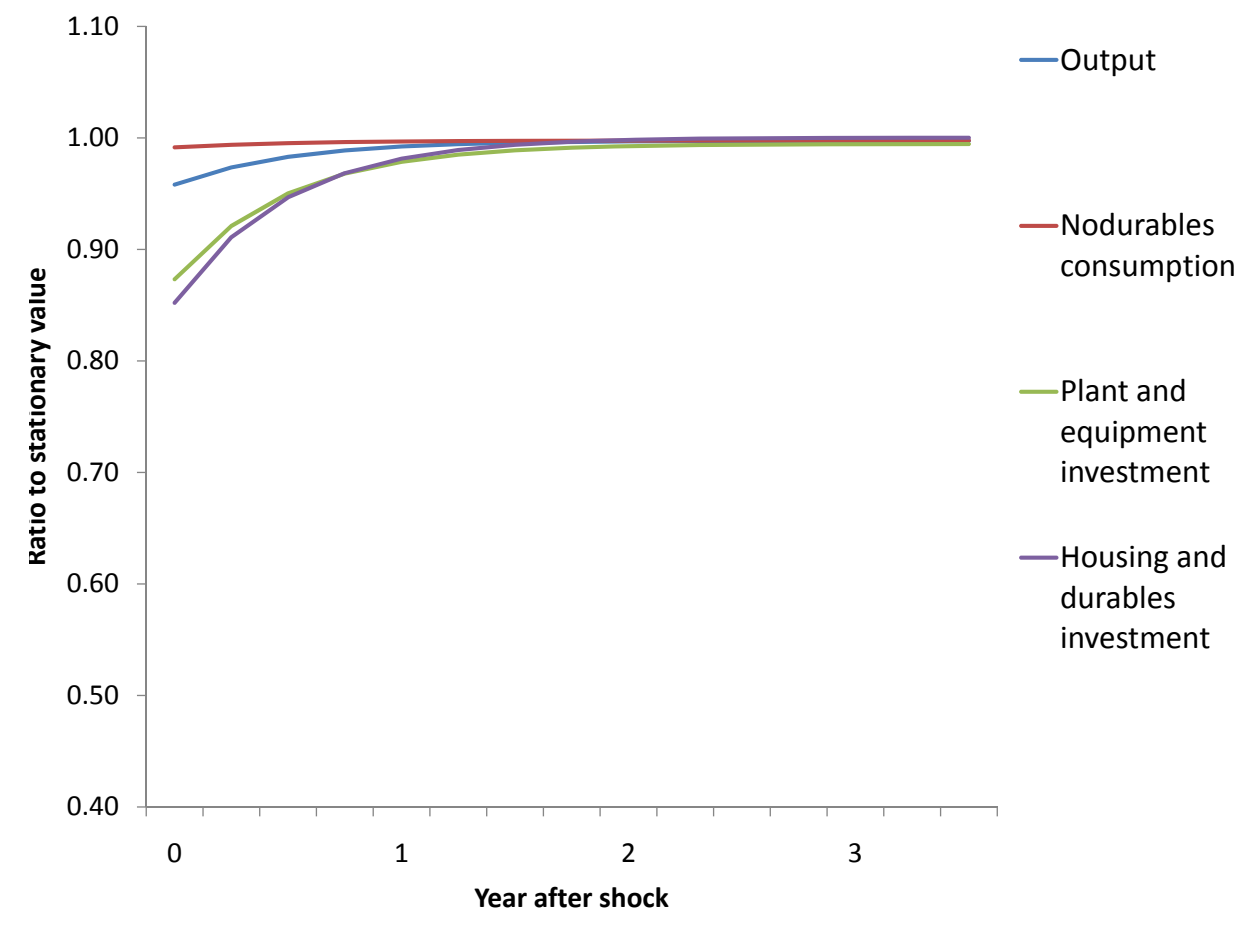

Figure 3: Response of Components of Output to Transitory Financial Friction

Table 4 compares the immediate response in the model to the actual changes in the U.S. economy around the time of the crisis in late 2008. Although the economy contracted sharply in the fourth quarter of 2008 relative to the third quarter, it seems more instructive to include another quarter before and after, to capture inertia present in the actual economy that is not considered in the model. The figures match reasonably well. The way I chose the magnitude of the shock accounts for the match of model to data for the decline in output, and the way I chose the adjustment cost for durables-housing accounts for the match for the decline in that category of investment. The matches for the small decline in nondurables consumption and the large decline in plant and equipment investment are genuine, in the sense that I picked no parameter or driving force to obtain the match. Hall (2009a) discusses the issues involved in specifying a model that avoids strong responses of consumption to driving forces.

Figure 4 shows the response of interest rates to the transitory financial friction. All rates in the model are real rates for borrowing for a single quarter. The immediate effect of the shock is to drive a wedge of 6 percentage points at annual rates between the borrowing rate, the upper line, and the lending rate, the lower line. The borrowing rate rises by 2.3 percentage points and the lending rate falls by the remaining 3.7 points. It is difficult to compare the response in the model to actual interest rates. Expectations about price 


\begin{tabular}{lcc}
\hline \hline & \multicolumn{2}{c}{ Percent decline } \\
\cline { 2 - 3 } & $\begin{array}{c}\text { US, 2008Q2 to } \\
\text { 2009Q1 }\end{array}$ & $\begin{array}{c}\text { Model, initial } \\
\text { quarter }\end{array}$ \\
\cline { 2 - 3 } Output & 4.3 & 4.2 \\
Consumption of nondurables and services & 1.1 & 0.8 \\
Investment in plant and equipment & 17.7 & 12.6 \\
Investment in housing and durables & 13.6 & 14.7 \\
\hline \hline
\end{tabular}

Table 4: Declines in Output and Components, U.S. Economy and Model

changes during the crisis appear to have been volatile, so translating the observed nominal rates into real rates is a challenge. Though there is an active market for price-level-indexed federal debt, those instruments appeared to suffer from valuation anomalies during the crisis. Further, their indexation does not apply when the price index falls below its level when the debt was issued. During the crisis, nominal yields on short-term federal debt fell to zero and were even slightly negative briefly. The term "flight to quality" is often applied to the phenomenon of low yields on safe debt during financial crises. From the perspective of the issues in this paper, a flight to quality is the same thing as a wedge that is unfavorable to private borrowing. The figure confirms that well over half the effect of the wedge is to depress safe interest rates rather than to raise private borrowing rates.

Figure 5 shows the response of prices to the transitory financial friction. Recall that all prices are stated in terms of units of composite consumption, so the analogy in the actual economy would be prices deflated by the consumption deflator. The biggest price change by far is the immediate decline in the rental price of plant and equipment. By contrast, only a tiny decline in the rental price of durables and housing occurs. Because output falls dramatically, the derived demand for the services of plant and equipment also falls, and the rental price falls to clear that market. Consumption smoothing implies that the demand for durables and housing services falls only a little, so the rental price is correspondingly stable. Because the two types of investment have the same Tobin investment equations and the responses of the investment flows are about the same, Tobin's $q$ follows similar paths for both types of capital in Figure 5. The rate of increase of $q_{k}$ is sufficiently higher to account for the lower rental price $p_{k}$.

The financial wedge drives down the prices of installed capital $\left(q_{k}\right.$ and $\left.q_{d}\right)$. The higher 


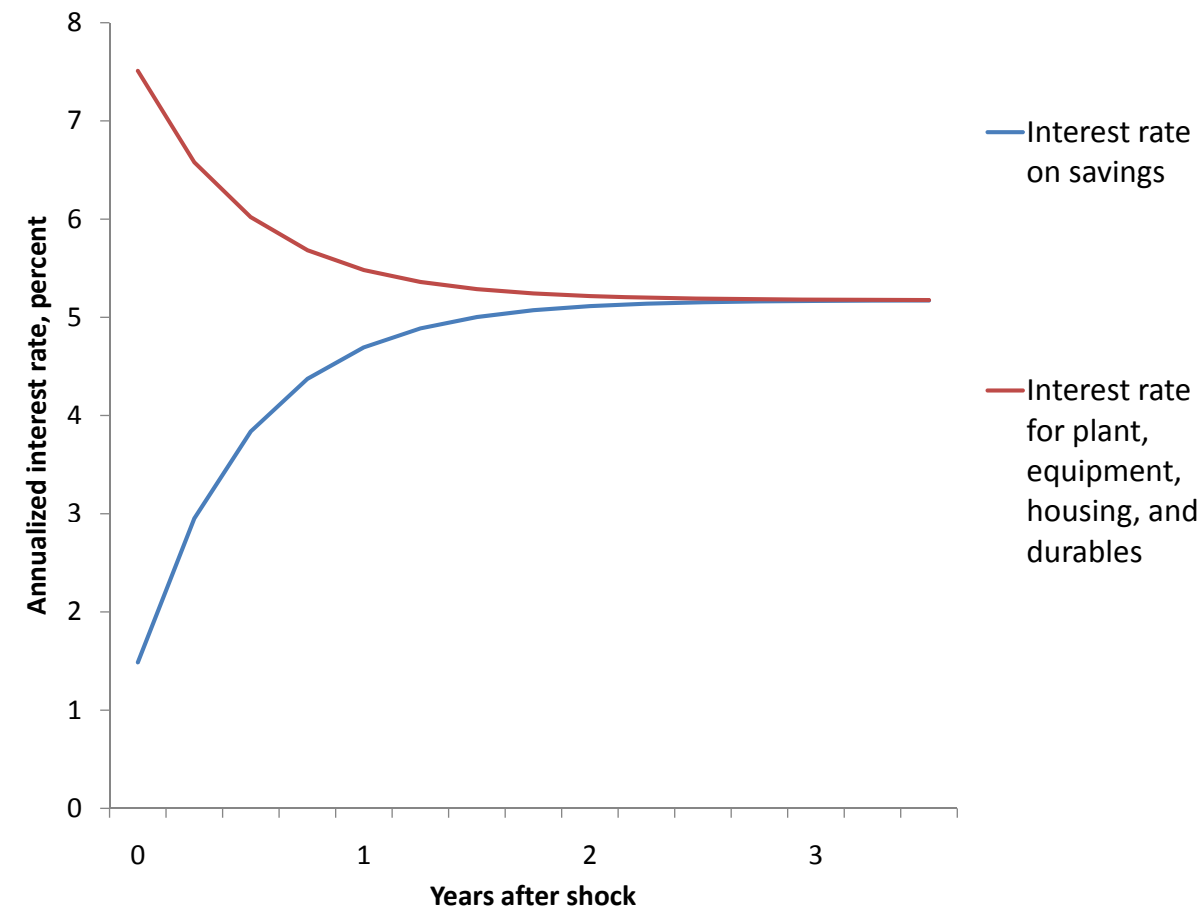

Figure 4: Response of the Interest Rates to Transitory Financial Friction

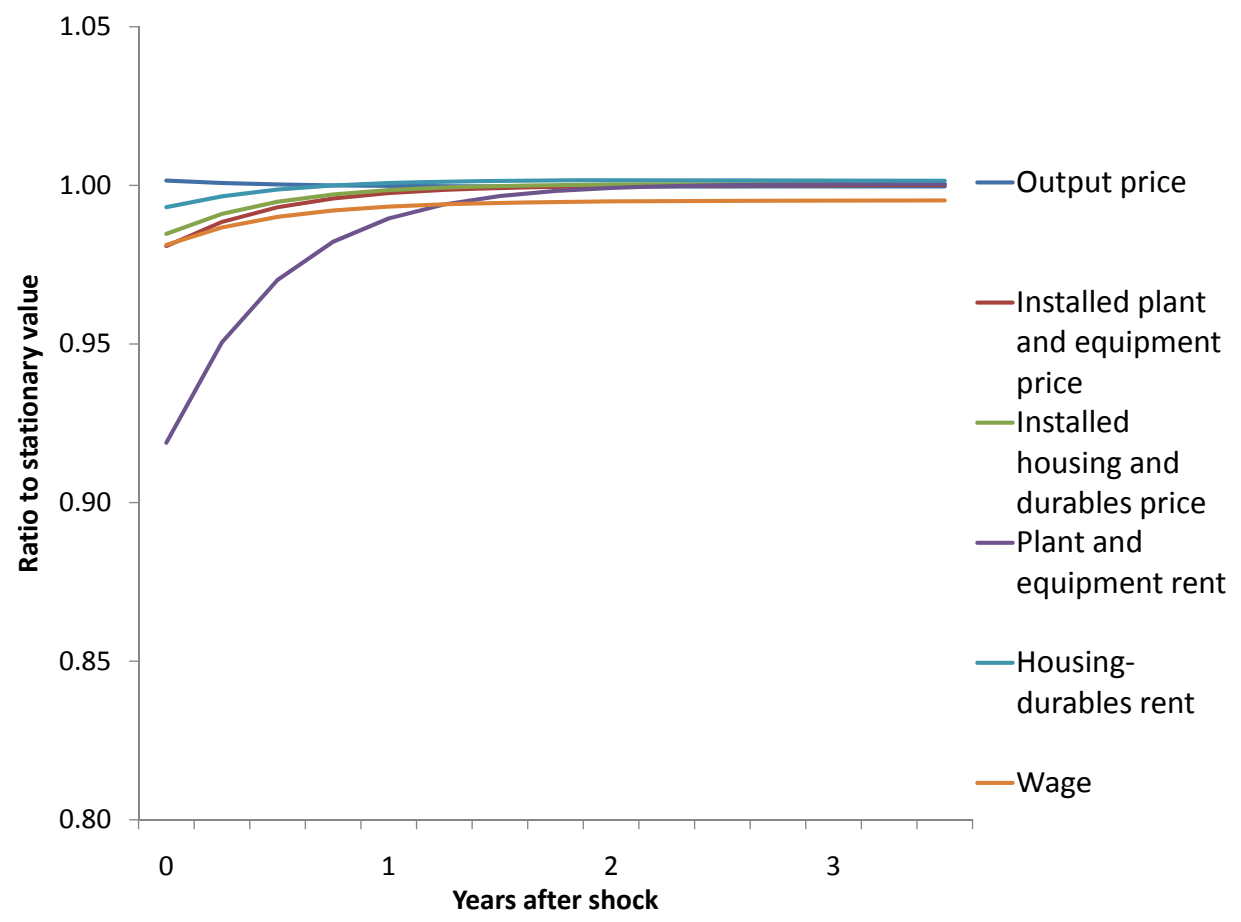

Figure 5: Response of Prices to Transitory Financial Friction 
cost of borrowing depresses demand for both types and-given less than fully elastic supply on account of adjustment costs-depresses those prices temporarily.

An immediate effect of the financial shock is to lower the real wage, reflecting the rise in the price/cost markup when output falls. Because the shock interrupts investment in plant and equipment, thus lowering the real wage even after the shock itself has worn off, the wage does not return to its stationary level over the three years shown in the figure. Only after decades does it return to that level.

The shock has almost no effect on the price of output, stated like the other prices relative to the price of composite consumption. The effect is small because most of composite consumption is ordinary output and the rest is the services of durables and housing, whose rental price falls only a little, lowering the price of composite consumption relative to the price of output.

\subsection{A more serious financial shock}

Table 5 shows the effect of a shock that raises the spread by 18 percentage points on impact, at an annual rate. As I noted earlier, a shock of this magnitude is needed to rationalize the increase in corporate bond spreads that occurred in late 2008, if the bond market realized that the shock would be transitory, with spreads returning to normal at 40 percent per quarter. Although the increase in spreads in short-term private credit markets were not close to 18 percent at annual rates, rationing became prevalent in those markets, so the observed spreads probably substantially understated the actual spreads.

The larger shock creates near-depression conditions, with output dropping by almost 12 percent and both categories of investment by about 40 percent. The safe interest rate falls to almost negative 12 percent, raising the question of how markets can achieve such negative rates at the same time that inflation is unlikely to be high and nominal rates cannot be negative.

\subsection{Responses when the zero lower bound on the safe nominal interest rate binds}

The model in this paper does not tackle any nominal issues. Its amplification mechanism delivers the same result as the Calvo sticky price setup in New Keynesian models, but without committing to the many strong assumptions usually made with that setup. Absent nominal 


\begin{tabular}{lcc}
\hline \hline & \multicolumn{2}{c}{ Declines, percent } \\
\cline { 2 - 3 } & Base case & $\begin{array}{c}\text { With three times } \\
\text { larger financial } \\
\text { shock }\end{array}$ \\
\hline Output & 4.2 & 11.6 \\
Nondurables consumption & 0.8 & 2.0 \\
Plant and equipment investment & 12.7 & 35.8 \\
Durables and housing investment & 14.8 & 42.2 \\
& & \\
& Changes in interest rates, \\
Rate received by savers & percentage points at annual rate \\
\cline { 2 - 3 } Rate paid by borrowers & -3.7 & -10.7 \\
\hline \hline
\end{tabular}

Table 5: Responses to Larger Financial Shock

elements, the model cannot deal with the nominal safe interest rate directly and thus cannot predict when the zero lower bound on that rate becomes a factor in the model. Hall (2009a) builds a standard New Keynesian model with a nominal anchor in the usual form of a Taylor rule. The model shares the same underlying real model with a model similar to the one in this paper but lacking a housing sector. The paper finds that, when the opposing force of the Taylor rule is disabled by the zero lower bound on the nominal interest rate (the central bank's policy instrument), the value of the elasticity of the markup ratio with respect to output rises. Amplification is stronger when the central bank is unable to offset a force that disturbs output and other aggregates. In the analysis of the adverse effects of an increase in the financial wedge, the point is that, at the zero lower bound, the central bank cannot use conventional stimulus - a lower safe nominal rate - to offset those adverse effects.

To incorporate a binding zero lower bound, I raise the markup elasticity parameter $\omega$ from its value of 1.03 in the base case to 1.25. Table 6 shows the higher response to the same financial shock (immediate increase of 6 percentage points at an annual rate in the wedge) in the base and zero-lower-bound cases. The decline in output becomes 6.6 percent compared to 4.2 in the base case. The decline remains concentrated in investment. The decline in the safe interest rate received by savers is actually smaller in the ZLB economy with higher amplification than in the base-case economy, but the rate paid by borrowers rises more in the ZLB case. 


\begin{tabular}{|c|c|c|}
\hline & \multicolumn{2}{|c|}{ Declines, percent } \\
\hline & Base case & $\begin{array}{c}\text { With binding zero } \\
\text { lower bound on } \\
\text { nominal rate }\end{array}$ \\
\hline Output & 4.2 & 6.6 \\
\hline Nondurables consumption & 0.8 & 2.2 \\
\hline Plant and equipment investment & 12.7 & 18.2 \\
\hline \multirow[t]{2}{*}{ Durables and housing investment } & 14.8 & 21.8 \\
\hline & \multicolumn{2}{|c|}{$\begin{array}{c}\text { Changes in interest rates, percentage } \\
\text { points at annual rate }\end{array}$} \\
\hline Rate received by savers & -3.7 & -3.0 \\
\hline Rate paid by borrowers & 2.3 & 3.0 \\
\hline
\end{tabular}

Table 6: Responses to Financial Shock under Zero Lower Bound

\section{The Roles of Key Parameters}

Table 7 compares the effects on impact of the 6-percentage-point rise in the financial wedge considered in the base case, for alternative values of some key parameters.

The second column of the table shows the importance of amplification through the markup elasticity, $\omega$. In the base case, the markup ratio falls by just over one percent for each percent increase in output. Removing this amplification by setting $\omega=0$ cuts the effect of the shock on output from 4.2 percent in the base case to only 1.5 percent. Consumption actually increases in response to the shock in this case. In a New Keynesian setting, this finding illustrates the importance of sticky prices. More generally, it shows that some amplification mechanism is a central component of models that generate substantial cyclical responses. Hall (2009a) finds a similar conclusion for the effect of government purchases - the multiplier is well below realistic levels in models that lack amplification.

The third column of Table 7 shows that an elastic response of labor input is also essential for the conclusion that financial shocks cause large responses of output and other aggregates. It uses a standard figure for the wage elasticity (in the Frisch sense) of labor supply from micro evidence, $\psi=0.7$, in place of the value in the base case, $\psi=1.9$. The difference of 1.2 accounts for the response of unemployment, as discussed in Hall (2009b). Including the elastic response of unemployment is essential - no reasonable account of macroeconomic responses to driving forces can ignore unemployment.

The fourth column of the table shows the dramatically increased impact of a more per- 


\begin{tabular}{|c|c|c|c|c|c|}
\hline & \multicolumn{5}{|c|}{ Declines, percent } \\
\hline & Base case & $\begin{array}{c}\text { Without } \\
\text { amplification } \\
\text { from markup: } \\
\quad \omega=0\end{array}$ & $\begin{array}{l}\text { Less elastic } \\
\quad \text { labor: } \\
\quad \psi=0.7\end{array}$ & $\begin{array}{c}\text { More } \\
\text { persistent } \\
\text { shock: } \\
\rho=0.9\end{array}$ & $\begin{array}{l}\text { No hours- } \\
\text { consumption } \\
\text { complemen- } \\
\text { tarity: } \chi=0\end{array}$ \\
\hline Output & 4.2 & 1.5 & 1.2 & 12.1 & 3.7 \\
\hline Nondurables consumption & 0.8 & -0.6 & -0.6 & 2.1 & -0.7 \\
\hline Plant and equipment investment & 12.7 & 6.1 & 5.4 & 43.8 & 14.1 \\
\hline \multirow[t]{2}{*}{ Durables and housing investment } & 14.8 & 8.4 & 6.3 & 24.0 & 17.2 \\
\hline & \multicolumn{5}{|c|}{ Changes in interest rates, percentage points at annual rate } \\
\hline Rate received by savers & -3.7 & -4.3 & -4.7 & -5.2 & -2.7 \\
\hline Rate paid by borrowers & 2.3 & 1.7 & 1.3 & 0.8 & 3.3 \\
\hline
\end{tabular}

Table 7: Impact Effects for Various Alternative Parameter Values

sistent shock. In the base case, the credit spread declines by 40 percent per quarter. In this alternative, the decline is only 10 percent per quarter $(\rho=0.9)$. The longer-lasting shock has almost triple the immediate impact on output as the quite transitory shock in the base case.

The fifth column of Table 7 removes the complementarity of consumption and work that is present in the base case, by setting $\chi=0$. This change reverses the sign of the effect of the financial shock on consumption - in the base case, the shock causes a small reduction in consumption, while in the alternative case, it causes a small increase in consumption. Recall that the consumption measure here excludes purchases of consumer durables. Without complementarity, the model suffers from the problem of many neoclassical models, that stimulus causes consumption to fall and adverse shocks cause consumption to rise, because consumption moves in the direction opposite of work effort and investment. Complementarity also has a modest effect of enlarging the effect of the financial wedge on output.

\section{Other Wedges}

This paper is about the powerful effect of an increase in a financial wedge on real activity. It does not intend to suggest that other wedges lack similar power. Table 8 compares the effect of the financial wedge in the base case to the effect of a standard labor wedge. The wedge separates the wage received by workers from the wage paid by employers. I choose 


\begin{tabular}{|c|c|c|}
\hline & \multicolumn{2}{|c|}{ Declines, percent } \\
\hline & $\begin{array}{l}\text { Base case-- } \\
\text { financial shock }\end{array}$ & Labor shock \\
\hline Output & 4.2 & 5.9 \\
\hline Nondurables consumption & 0.8 & 3.1 \\
\hline Plant and equipment investment & 12.6 & 13.7 \\
\hline \multirow[t]{2}{*}{ Durables and housing investment } & 14.7 & 15.5 \\
\hline & \multicolumn{2}{|c|}{$\begin{array}{c}\text { Changes in interest rates, } \\
\text { percentage points at annual rate }\end{array}$} \\
\hline Rate received by savers & -3.7 & 1.6 \\
\hline Rate paid by borrowers & 2.3 & 1.6 \\
\hline
\end{tabular}

Table 8: Comparison of Response to Financial and Labor Shocks

the labor wedge so that it has the same proportional effect on the wage that the financial wedge has on the rental price of capital. The wedge is 3.7 percent; it is equivalent to adding 3.7 percentage points to a payroll tax that applies to all labor input.

The labor wedge has a larger adverse effect on output than does the financial wedge. Most of the difference is in its effect on consumption, which falls by 3.1 percent in the labor case and only 0.8 percent in the financial case. The effects on both categories of investment are similar for the two wedges. The labor wedge raises both interest rates by 1.6 percentage points.

\section{Concluding Remarks}

The financial wedge is a potent determinant of economic activity. Increases in credit spreads in the range seen in the crisis of late 2008 appear to include significant elements that act as increased wedges, although rising default probabilities and financial risk were also factors accounting for the rise in spreads. An increase at the initial level of 6 percentage points in the financial wedge causes reductions in output and investment comparable to those that occurred in the United States following the crisis.

The literature relating credit spreads to earlier fluctuations together with the results here lead to the conclusion that financial frictions should be included among the leading driving 
forces of recessions and booms in macroeconomic thinking. With evidence that productivity shocks are no longer positively correlated with economic activity, the finding that financial events operate through a powerful channel and are large enough and correlated enough with activity should result in improved understanding of the multiple sources of aggregate fluctuations.

The model supporting these conclusions has some controversial features. The model relies on the interaction of two structural sources of amplification that are non-standard from the perspective of normal economic principles: (1) the general wedge separating work from consumption captured by the markup of price over cost shrinks when output rises, and (2) unemployment, as determined by the principles of a generalized Mortensen-Pissarides framework, declines when workers become more productive. Empirical support for countercyclical markups is weak - see Hall (2009a) for a review. Though the countercyclical nature of unemployment is unchallenged, researchers hold many different views about its determination. Much work remains to be done on the key issue of amplification. 


\section{References}

Amato, Jeffery D. and Eli M. Remolona, "The Credit Spread Puzzle," BIS Quarterly Review, December 2003, pp. 51-63.

Chari, V. V., Patrick J. Kehoe, and Ellen R. McGrattan, "Business Cycle Accounting," Econometrica, 05 2007, 75 (3), 781-836.

Christiano, Lawrence J. and Joshua M. Davis, "Two Flaws In Business Cycle Accounting," NBER Working Papers 12647, National Bureau of Economic Research, Inc October 2006.

Cúrdia, Vasco and Michael Woodford, "Credit Frictions and Optimal Monetary Policy," May 2009.

Gertler, Mark and Nobuhiro Kiyotaki, "Financial Intermediation and Credit Policy in Business Cycle Analysis," in Benjamin Friedman and Michael Woodford, eds., Handbook of Monetary Economics, Elsevier, 2010, p. forthcoming.

and Peter Karadi, "A Model of Unconventional Monetary Policy," April 2009.

Gilchrist, Simon, Vladimir Yankov, and Egon Zakrajsek, "Credit Market Shocks and Economic Fluctuations: Evidence from Corporate Bond and Stock Markets," NBER Working Papers 14863, National Bureau of Economic Research, Inc April 2009.

Hall, Robert E., "Measuring Factor Adjustment Costs," Quarterly Journal of Economics, August 2004, 119 (3), 899-927.

—_ "By How Much Does GDP Rise If the Government Buys More Output?," Brookings Papers on Economic Activity, 2009, (2), forthcoming.

_ _ "Reconcilling Cyclical Movements in the Marginal Value of Time and the Marginal Product of Labor," Journal of Political Economy, April 2009, 117 (2), 281-323.

Hellwig, Martin, "Systemic Risk in the Financial Sector: An Analysis of the SubprimeMortgage Financial Crisis," Technical Report, Max Planck Institute for Research on Collective Goods, Bonn November 2008. 
Kiyotaki, Nobuhiro and John Moore, "Liquidity, Business Cycles, and Monetary Policy," April 2008.

Philippon, Thomas, "The Bond Market's q," Quarterly Journal of Economics, August 2009, $124(3), 1011-1056$.

Stein, Jeremy, "Agency, Information, and Corporate Investment," in G.M. Constantinides, M. Harris, and R. Stulz, eds., Handbook of the Economics of Finance, Elsevier, 2003, chapter 2, pp. 109-163. 


\section{Appendix}

\section{A Model Details}

The approach is to find the exact solution to a perfect-foresight version of the model. Experience has shown that the solution to the perfect-foresight model, starting just after a shock has displaced the model from its stationary point, provides a good approximation to the expected path of a full stochastic model perturbed by the same shock. A full solution to the stochastic model requires much more advanced numerical methods. With a small shock, the method used here gives essentially the same results as the standard log-linearization.

\section{A.1 Timing and boundary conditions}

I use a timing convention suitable for Matlab: Period 1 describes the economy before a shock and provides initial conditions. The shock affects period 2 and later. The last economic decisions occur in period $T$. Capital at the end of period $T$ is required to be at the economy's stationary level: $k_{T}=k^{*}$ and similarly for the stock of housing $d$. For a reasonably large value of $T$, the result is very close to the infinite-horizon solution.

Variables requiring initial values in period 1 are capital $k_{1}$, I use the values $k_{1}=k^{*}$.

\section{A.2 Summary of core model}

Core variables: $y, p_{y}, k, d, r, w, c, p_{k}$, and $p_{d}$

$$
\begin{gathered}
y_{t}=h_{t}^{\alpha} k_{t-1}^{1-\alpha} \\
(1-\alpha) \frac{p_{y, t} y_{t}}{\mu_{t} p_{k, t}}=k_{t-1} \\
p_{d, t} d_{t-1}=(1-\phi) c_{t} \\
w_{t} c_{t}^{-1 / \sigma}\left[1-\chi(1-1 / \sigma) h^{1+1 / \psi}\right]=p_{c, t} h^{1 / \psi}\left[-\chi(1+1 / \psi) c^{1-1 / \sigma}-1\right] \\
\left(1+r_{t}\right) m_{t}=1
\end{gathered}
$$




$$
\begin{gathered}
y_{t}=c_{y, t}+g_{t}+k_{t}-\left(1-\delta_{k}\right) k_{t-1}+\frac{\kappa_{k}}{2} \frac{\left(k_{t}-k_{t-1}\right)^{2}}{k_{t-1}}+d_{t}-\left(1-\delta_{d}\right) d_{t-1}+\frac{\kappa_{d}}{2} \frac{\left(d_{t}-d_{t-1}\right)^{2}}{d_{t-1}} \\
\phi^{-\phi}(1-\phi)^{-(1-\phi)} p_{y, t}^{\phi} p_{d, t}^{1-\phi}=1 \\
p_{k, t}=\left(1+r_{t-1}\right)\left(1+f_{t-1}\right) q_{k, t-1} p_{y, t-1}-\left(1-\delta_{k}\right) q_{k, t} p_{y, t} \\
p_{d, t}=\left(1+r_{t-1}\right)\left(1+f_{t-1}\right) q_{d, t-1} p_{y, t-1}-\left(1-\delta_{d}\right) q_{d, t} p_{y, t}
\end{gathered}
$$

\section{A.3 Summary of auxiliary model}

Auxiliary variables: $h, q_{k}, q_{d}, c_{y}, m$, and $\mu$.

$$
\begin{gathered}
h_{t}=\alpha \frac{p_{y, t} y_{t}}{\mu w_{t}} \\
q_{k, t}=\kappa_{k} \frac{k_{t}-k_{t-1}}{k_{t-1}}+1 \\
q_{d, t}=\kappa_{d} \frac{d_{t}-d_{t-1}}{d_{t-1}}+1 \\
c_{y, t}=\phi \frac{c_{t}}{p_{y, t}} \\
m_{t, t+1}=\frac{c_{t+1}^{-1 / \sigma}}{c_{t}^{-1 / \sigma}} \frac{1-\chi(1-1 / \sigma) h_{t+1}^{1+1 / \psi}}{1-\chi(1-1 / \sigma) h_{t}^{1+1 / \psi}} \\
\mu_{t}=\left(\frac{y_{t}}{\bar{y}}\right)^{-\omega}
\end{gathered}
$$

Exogenous variables: $g, f_{k}, f_{d}$ 


\section{A.4 Solution}

The model has $9 T-12$ unknowns: Values of $y, p_{y}, w, c, p_{k}$, and $p_{d}$ in periods 2 through $T$ $(6(T-1)$ unknowns) and $r, k$, and $d$ in periods 2 through $T-1(3(T-2)$ unknowns). It has $9 T-12$ equations: the Euler equation spanning observation pairs $(2,3)$ through $(T-1, T)$ ( $T-2$ equations), the two rental price equations for observations 3 through $T(2(T-2)$ equations), and the 6 other equations for periods 2 through $T(6(T-1)$ equations). I solve the equations for all periods simultaneously.

\section{A.5 Stationary model}

Core: Variables: $y, k, w, d, c, p_{y}$

$$
\begin{gathered}
y=h^{\alpha} k^{1-\alpha} \\
(1-\alpha) \frac{p_{y} y}{p_{k}}=k \\
p_{d} d=(1-\phi) c \\
w c^{-1 / \sigma}\left[1-\chi(1-1 / \sigma) h^{1+1 / \psi}\right]=p_{c} h^{1 / \psi}\left[-\chi(1+1 / \psi) c^{1-1 / \sigma}-1\right] \\
y-c_{s}-g-\delta_{k} k-\delta_{d} d=0 \\
1=\phi^{-\phi}(1-\phi)^{-(1-\phi)} p_{y}^{\phi} p_{d}^{1-\phi}
\end{gathered}
$$

Auxiliary:

$$
\begin{gathered}
(1+r) \beta=1 \\
h=\alpha \frac{p_{y} y}{w} \\
p_{k}=p_{y}\left(r+\delta_{k}\right) \\
p_{d}=p_{y}\left(r+\delta_{d}\right)
\end{gathered}
$$




$$
c_{s}=\phi \frac{c}{p_{y}}
$$

\section{B Calibrating Preferences}

The first-order conditions for the Frisch system are:

$$
c^{-1 / \sigma}\left[1-\chi(1-1 / \sigma) h^{1+1 / \psi}\right]=\lambda p_{c}
$$

and

$$
h^{1 / \psi}\left[\chi(1+1 / \psi) c^{1-1 / \sigma}+1\right]=\lambda w .
$$

Let $\hat{c}=\log (c), \hat{h}=\log (h)$, and $\hat{p}=\log \left(\lambda p_{c}\right)$. Then

$$
-\frac{1}{\sigma} \hat{c}+\log \left(1-\chi(1-1 / \sigma) e^{(1+1 / \psi) \hat{h}}\right)=\hat{p}
$$

and

$$
\frac{1}{\psi} \hat{h}+\log \left(\chi(1+1 / \psi) e^{(1-1 / \sigma) \hat{c}}+1\right)=\hat{w}
$$

SO

$$
\begin{gathered}
-\frac{1}{\sigma} \frac{d \hat{c}}{d \hat{p}}-\left[1-\chi(1-1 / \sigma) e^{(1+1 / \psi) \hat{h}}\right]^{-1} \chi(1-1 / \sigma)(1+1 / \psi) e^{(1+1 / \psi) \hat{h}} \frac{d \hat{h}}{d \hat{p}}=1, \\
\frac{1}{\psi} \frac{d \hat{h}}{d \hat{w}}+\left[\chi(1+1 / \psi) e^{(1-1 / \sigma) \hat{c}}+1\right]^{-1} \chi(1-1 / \sigma)(1+1 / \psi) e^{(1-1 / \sigma) \hat{c}} \frac{d \hat{c}}{d \hat{w}}=1,
\end{gathered}
$$

and

$$
-\frac{1}{\sigma} \frac{d \hat{c}}{d \hat{w}}-\left[1-\chi(1-1 / \sigma) e^{(1+1 / \psi) \hat{h}}\right]^{-1} \chi(1-1 / \sigma)(1+1 / \psi) e^{(1+1 / \psi) \hat{h}} \frac{d \hat{h}}{d \hat{w}}=0
$$

I use values from earlier research on the two direct Frisch elasticities, $F_{c, c}=d \hat{c} / d \hat{p}$ and $F_{h, h}=d \hat{h} / d \hat{w}$. In addition, to calibrate the cross elasticity, I use evidence on the ratio of consumption when hours are zero to consumption when hours are normal. Let that ratio be $\eta$. Then, equating marginal utility for the employed and unemployed, I find

$$
c^{-1 / \sigma}\left[1-\chi(1-1 / \sigma) h^{1+1 / \psi}\right]=(\eta c)^{-1 / \sigma} .
$$

I rewrite the three conditions for the Frisch elasticities in terms of $c$ and $h$ and let the cross Frisch elasticities be called $F_{c, h}=-F_{h, c}$ :

$$
-\frac{1}{\sigma} F_{c, c}+\left[1-\chi(1-1 / \sigma) h^{1+1 / \psi}\right]^{-1} \chi(1-1 / \sigma)(1+1 / \psi) h^{1+1 / \psi} F_{c, h}=1,
$$




$$
\frac{1}{\psi} F_{h, h}+\left[\chi(1+1 / \psi) c^{1-1 / \sigma}+1\right]^{-1} \chi(1-1 / \sigma)(1+1 / \psi) c^{1-1 / \sigma} F_{c, h}=1
$$

and

$$
-\frac{1}{\sigma} F_{c, h}-\left[1-\chi(1-1 / \sigma) h^{1+1 / \psi}\right]^{-1} \chi(1-1 / \sigma)(1+1 / \psi) h^{1+1 / \psi} F_{h, h}=0 .
$$

I include the four equations (71) through (74) in the calibration solution, treating $\sigma, \psi, \chi$, and $F_{c, h}$ as four unknowns, with $F_{c, c}, F_{h, h}$, and $\eta$ known. Following Hall (2009b), I take $F_{c, c}=-0.5, F_{h, h}=1.9$, and $\eta=0.85$. For an extensive discussion of the calibration, see Hall (2009a).

\section{Matlab Implementation}

Function CModel $(x)$ takes a vector of stacked values of the core variables and calculates discrepancies for the core equations. It calculates auxiliary variables from the core variables as needed. The vector $x$ is a solution to the model when CModel delivers a vector of zeros to the designated precision. Function $\operatorname{StatModel}(x)$ takes a vector $x=\left[y, k, w, d, c, p_{y}, \sigma, \psi, \chi, F_{c h}\right]$ and calculates discrepancies for the core equations that apply to the stationary version of the model.

Program CMain uses Matlab library function fsolve and function StatModel to find the stationary values of all of the core variables. Then it solves for the vector of the 1428 values of the core variables for the dynamic solution using fsolve and CModel. It can solve the model for a variety of parameter values in one run. It stores the results in Excel file Results.xlsx. Be sure this file is closed when running the Matlab program, as Matlab cannot write into an open Excel file.

\section{Capital Dynamics}

The model follows its capital dynamics when all of the exogenous driving forces are constant at their stationary levels and the only departures of the endogenous variables from their stationary values arise from the departures of the state variables - the capital and housingdurable stocks - from their stationary levels. The model follows its dynamic path back to its stationary point. I start by displaying the path because all shocks, once the shock itself subsides, causes the economy to follow the same path in the longer run, back to its stationary point. Figure 6 shows the endogenous path of the components of output when the capital 


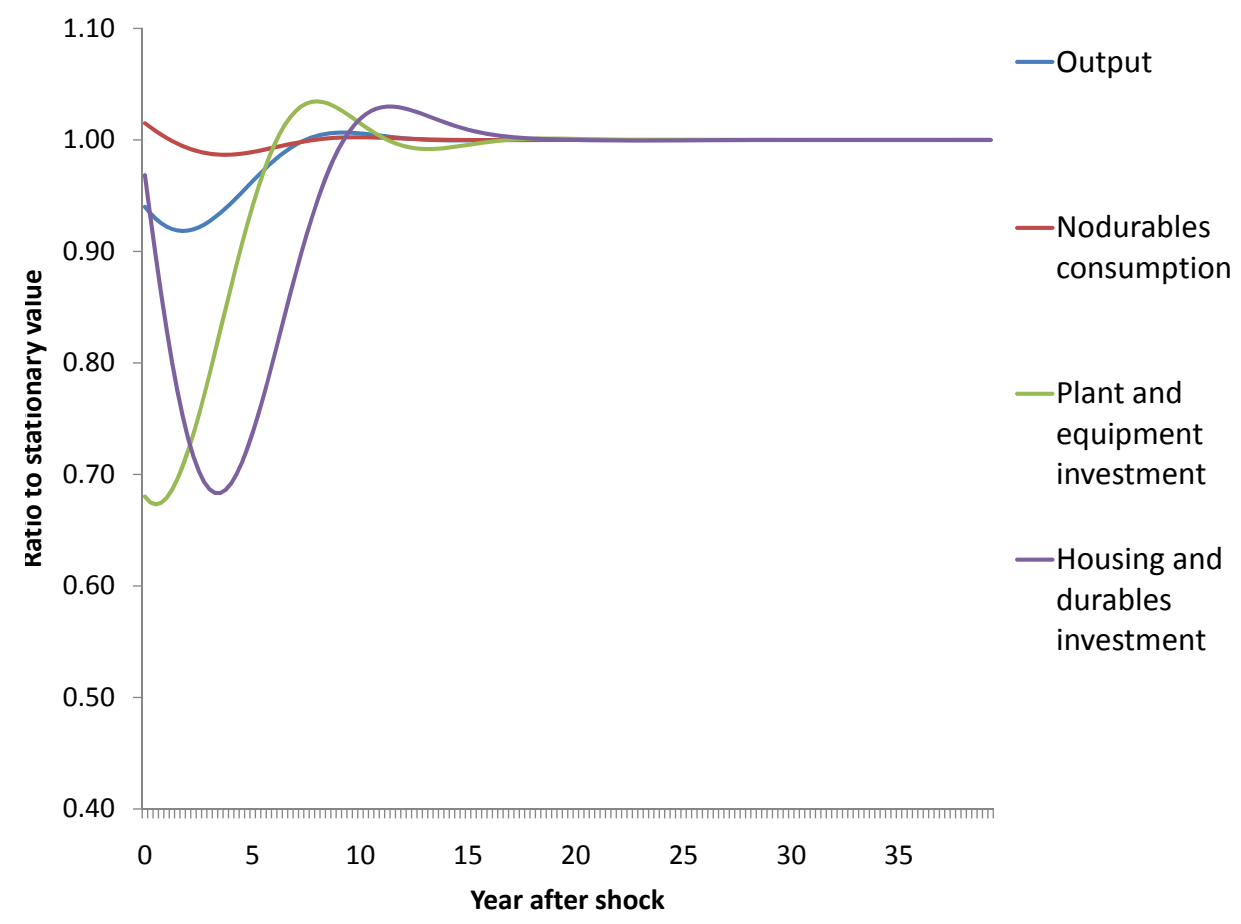

Figure 6: Endogenous Dynamic Paths of Components of Output

stock and the stock of housing and durables both start 5 percent above their stationary values.

At first, investment in plant and equipment is below its stationary level, as expected. On the other hand, investment in durables and housing is above it stationary level. The reason for the latter behavior is that the stock of durables and housing remains above its stationary level and the equilibrium calls for continuing to replace the high level, though the stock of durables is declining toward its stationary level from the start. The asymmetry arises from the difference in the depreciation rates for the two kinds of capital. Output starts at its stationary level - the changes in consumption and the two categories of investment almost exactly offset one another-then sags to a minimum at 6 years and then recovers to its stationary level. Consumption starts a bit above its stationary level and then declines.

Figure 7 shows the endogenous path of the interest rate. Because there is no financial friction over the period, all three rates in the model are the same. The surplus of the two kinds of capital over their stationary levels results in an extended period of low interest rates.

Figure 8 shows the endogenous paths of the economy's prices, all stated in units of consumption and normalized to be one at the economy's stationary point. The wage starts at a high level, reflecting the higher marginal product of labor with the extra capital, and 


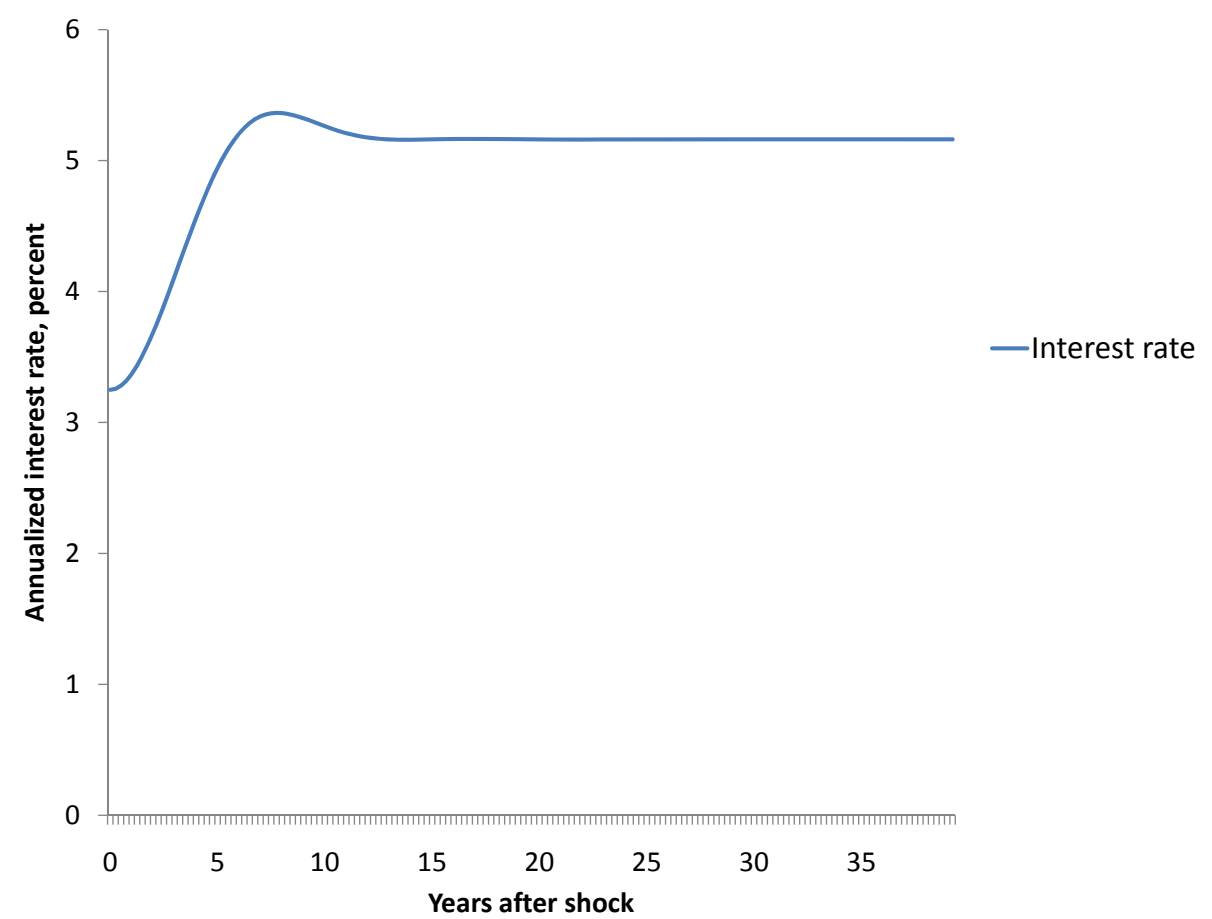

Figure 7: Endogenous Dynamic Path of the Interest Rate

declines to its stationary value. The price of output starts somewhat above one and declines to one as well. The price of output in consumption units is above one at the outset because the rental price of housing is below one and consumption is thus cheaper than output. The prices of installed capital, start below $\left(q_{k}\right)$ or at $\left(q_{d}\right)$ the price of output, because the capital stocks are falling or are constant. The rental prices of both kinds of capital start below their stationary levels because of the excess of both stocks over their stationary levels. 


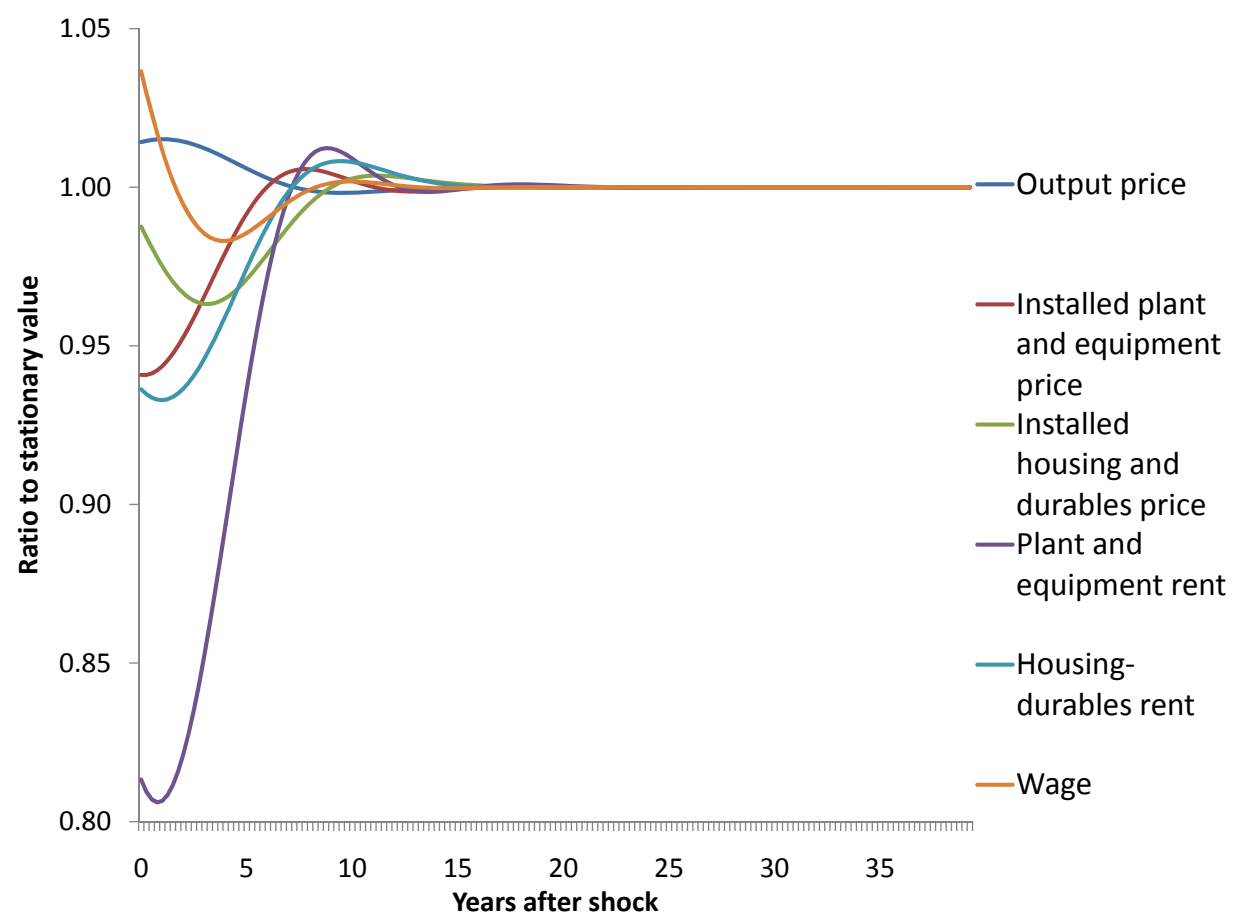

Figure 8: Endogenous Dynamic Path of Prices 